\title{
A Study on Information Processing by Human Brain
}

\author{
Geetha Shavali $^{1}$, K. Devika² \\ ${ }^{1}$ Assistant Professor,Upgraded Dept. of Physiology, Osmania Medical College, \\ ${ }^{2}$ Final year Postgraduate, Upgraded Dept. of Physiology, Osmania Medical College
}

\begin{abstract}
Background: Information gathering and processing by human brain has always perplexed the scientific world. Few evidenced it to be in an analog form while a second school of thought showed it to be digital. There were also a third group who believed it was neither analog nor digital but followed a special signal processing paradigm ${ }^{[1]}$. A small attempt has been made in this study to assess the mode of information grasping by human brain.

Materials and Method: Two hundred and fifty undergraduate students studying first year of MBBS (Bachelor of Medicine and Bachelor of Surgery) at Osmania Medical College, Hyderabad were selected for the study after taking consent from institutional ethics committee. An article consisting of 110 words written in jumbled alphabets was selected for the study. As the average reading speed of human beings is 200 to 250 words per minute, the students were instructed to read the article within half a minute and to jot down the words not understood by them on a white sheet. At the end white sheets of all 250 students were collected.
\end{abstract}

\section{Conclusions:}

1. The study concludes that on a time scale human brain tries to grasp maximum information in minimum time possible, i.e. it takes and processes the information in an analog form

2. Later if needed only it digitalises the information and learns the details.

3. On a temporal framework grasping the information in an analog form gives advantage to the biological system

Keywords: Analog,biological system, digital, signal processing paradigm, temporal framework.

\section{Introduction}

Biological systems are complex macromolecular systems which acquire, store, process and use information to organise their activities. How the brain represents information has real world impact on how capable we are of dealing with the complexity of reality ${ }^{[2]}$. Neural systems have evolved to maximise their information transmission rate. For this, different parts of the brain may process the signals in different ways ${ }^{[3]}$.Information in humans is stored in two places, the genes and the brain. It is stored as digital information in genes whereas in brain it is still a mystery. Processing of information by the brain can be both digital and analog. Analog deals with continuous signal representing physical measurements relating to the whole form. Digital deals with time separated signals represented by sequence of discrete variables. For example, Long Playing(LP) record is analog, whereas Compact Disc(CD) record is digital. The human brain processes the information in either form(analog or digital) ${ }^{[4]}$, to the advantage of the biological system appropriate to the time, place, person and need. On a temporal framework, it tries to grasp maximum information in minimum time possible. For this to be achieved it may overlook the details or finer aspects. That is to say it grasps the information in an analog form to get an overall picture. Whereas when it is given adequate time, it tries to grasp the details and the finer aspects i.e. information grasping in digital form. A small attempt has been made in this study to account for this temporal processing. 


\section{Materials and Method}

Two hundred and fifty undergraduate students studying first year of MBBS (Bachelor of Medicine and Bachelor of Surgery) at Osmania Medical College, Hyderabad were selected for the study after taking consent from institutional ethics committee. An article consisting of 110 words written in jumbled alphabets was selected for the study. As the average reading speed of human beings is 200 to 250 words per minute, the students were instructed to read the articleh within half a minute and to jot down the words not understood by them on a white sheet. At the end white sheets of all 250 students were collected.

\section{Article:}

fi yuo cna raed tihs, yuo hvae a sgtrane mnid too. I cdnuolt blveiee taht I cluod aulacity uesdnatnrd waht I was rdanieg. The phaonmneal pweor of the hmuan mnid, aoccdrnig to a rscheearch at Cmabrigde Uinervtisy, it dseno't mtaetr in waht oerdr the Itteres in a wrod are, the olny iproamtnt tihng is taht the frsit and Isat Itteer be in the rghit pclae. The rset can be a taotl mses and you can sitll raed it whotuit a pboerlm. Tins is bcuseae the huamn mnid deos not raed ervey lteter by istlef, but the wrod as a wlohe. Azanmig huh? Yaeh and I awlyas tghuhot slpeling was ipmorantt!

\section{Results}

2 out of 250 students $(0.8 \%)$ could grasp every word $100 \%$ of the article.

18 students (7.2\%) could make out 108 words out of 110 i.e. $\mathbf{9 8 . 1 8 \%}$ of the article. They could not make out onlytwo words.

148 students (59.2\%) could make out 107 words out of 110 i.e. $97.27 \%$ of the article. They could not make out only three words.

20 students (8\%) could make out 106 words out of 110 i.e. $\mathbf{9 6 . 3 6 \%}$ of the article. They could not make out four words.

32 students $(12.8 \%)$ could make out 105 words out of 110 i.e. $\mathbf{9 5 . 4 5 \%}$ of the article. They could not make out five words.

30 students (12\%) could make out 104 words out of 110 i.e. $\mathbf{9 4 . 5 4 \%}$ of the article. They could not make out six words.

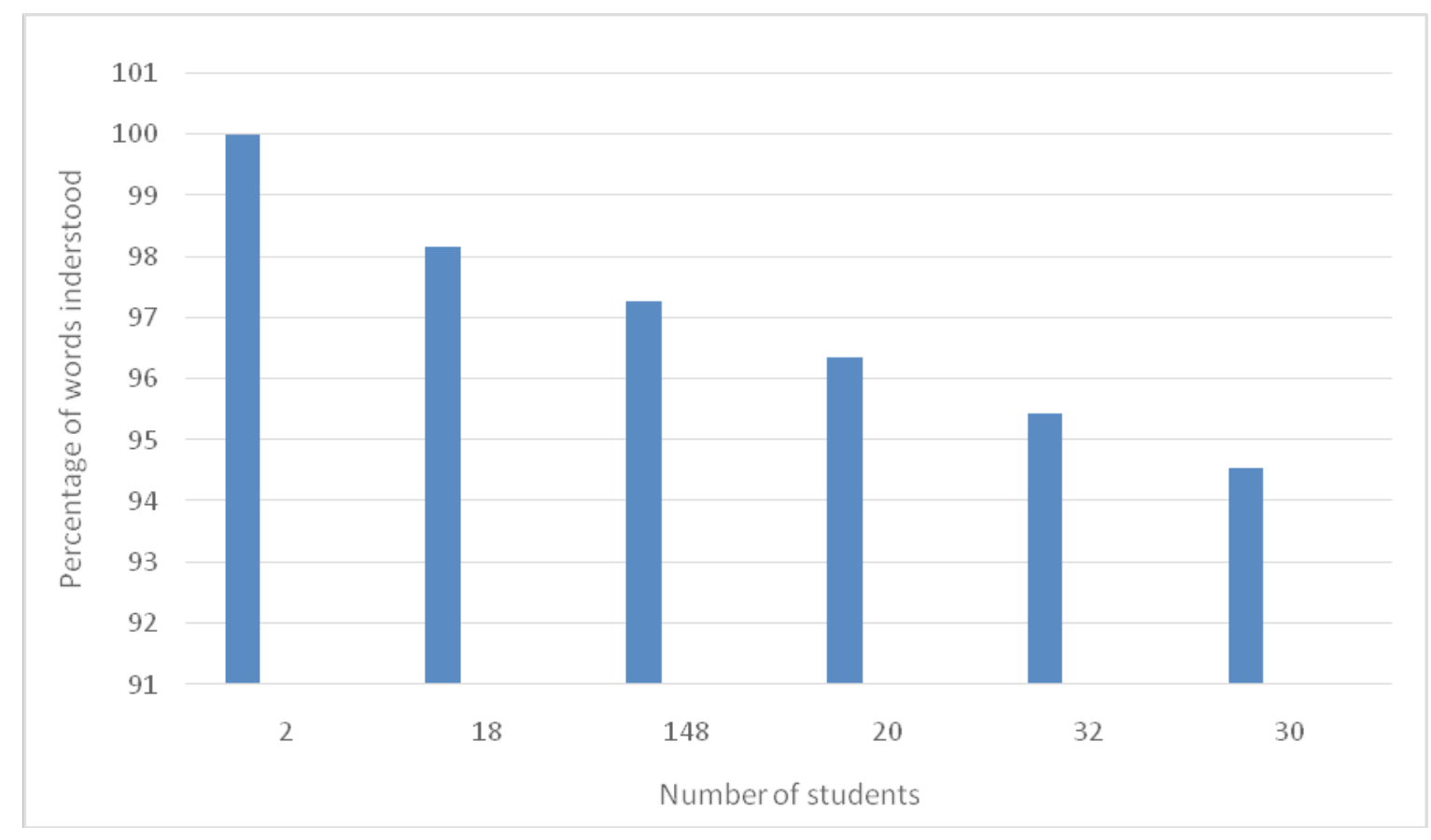


The words which the students could not make out were:

i. Cdnuolt (couldn't)

ii. Aulaclty (actually)

iii. Taht (that)

iv. waht (what)

v. taotl (total)

vi. tghuhot (thought)

vii. whotuit (without)

viii.bcuseae (because)

ix. mtaetr (matter)

x. rdanieg (reading)

\section{Discussion}

All two hundred and fifty students could identify the maximum number of words and the information conveyed in the article. They grasped each word as a whole and not each letter or spelling of the word. They concentrated on the spellings only when they could not make out the word. The context also helped them in identification of the words in the article. They grasped the information in analog form and digitalised the words only when they did not understand. This proves that the human brain always tries to accumulate maximum information in minimum time possible to use it when the need arises.

\section{Conclusions}

1. The study concludes that on a time scale human brain tries to grasp maximum information in minimum time possible, i.e. it takes and processes the information in an analog form.

2. Later if needed only it digitalises the information and learns the details.

3. On a temporal framework grasping the information in an analog form gives advantage to the biological system

Ethical Clearance: Taken from Osmania Medical College Ethics committee.

\section{Source of Funding: Self \\ Conflict of Interest: Nil}

Acknowledgement: I am very thankful to all two hundred and fifty undergraduate students of batch 20192020 first year MBBS who readily agreed to participate in the study.

\section{References}

1. Paul king, Director of Data science, Computational Neuroscientist. Is the human brain analog or digital? - Forbes 26 september 2016 https://www. forbes.com/sites/quora/2016/09/27/is-the-humanbrain-analog-or-digital/\#312aedc77106

2. Robin Harris Is your brain an analog or digital device - New research surprises 22 June 2018 https://www.zdnet.com/article/is-your-brainanalog-or-digital/

3. Yasuhiro Mochizuki, Kyoto University Shigeru Shinomoto, Kyoto University Analog and digital codes in the brain November 2013 Physiological Review E 89(2) DOI: 10.1103/ PhysRevE.89.022705 https://www.researchgate. net/publication/258566698_Analog_and_digital_ codes_in_the_brain

4. Solving the Neural code Conundrum: Digital or Analog? 26 November 2013 https://www. technologyreview.com/2013/11/26/82730/solvingthe-neural-code-conundrum-digital-or-analog/ 